\title{
Surgical Correction of Subluxing Peroneal Tendons Utilizing a Lateral Slip of the Achilles Tendon: A case report
}

\author{
by Mark Mendeszoon, DPM, FACFAS, FAFAOM ${ }^{1} \otimes$, J. Todd McVey, DPM ${ }^{2}$, Adam MacEvoy, DPM ${ }^{3} \otimes$
}

The Foot and Ankle Online Journal 2 (8): 3

Subluxation of the peroneal tendon can be either an acute or chronic condition. As an acute injury, it can quite often be misdiagnosed as a lateral ankle sprain. This case report describes a technique using the lateral slip of the Achilles tendon as a retinacular graft to repair subluxation and dislocation of the peroneal tendons.

Key words: Tubularization, Achilles tendon graft, modified Brostrom repair, subluxation, dislocation, peroneal tendons.

Accepted: July, 2009 Published: August, 2009

This is an Open Access article distributed under the terms of the Creative Commons Attribution License. It permits unrestricted use, distribution, and reproduction in any medium, provided the original work is properly cited. (The Foot and Ankle Online Journal (www.faoj.org)

$\mathrm{T}$ he peroneal tendons course around the lateral ankle at the distal aspect of the fibula. These tendons which include the tendons of the peroneus longus and brevis move through a tunnel created of both fibrous and osseous structures. ${ }^{2}$ The borders of this tunnel include the lateral malleolus, posterior talofibular ligament, calcaneal fibular ligament, and superior peroneal retinaculum. Both tendons run together until they are distal to the fibula where they split and enter separate sheaths. Most important to us is the superior peroneal retinaculum (SPR) which is the primary restraint to subluxation and dislocation of the peroneal tendons. ${ }^{1,8,9}$

First Described in 1803 by Monteggia, peroneal subluxation and dislocation can be categorized as either acute or chronic injuries. Most acute injuries are caused by a sudden dorsiflexion and inversion of the ankle while the peroneals are contracting. Acute injuries occur most often during sporting activities.

Address correspondence to: Adam MacEvoy, DPM. PGY III, Department Of Veterans Affairs. Louis Stokes Cleveland Medical Center. Podiatry

Surgery . Cleveland Ohio 44106. (216) 791-3800 Ext 5891

${ }^{1}$ Precision Orthopedics, $1507^{\text {th }}$ Ave, Chardon, Ohio 44024.

2 Department Of Veterans Affairs. Louis Stokes Cleveland Medical Center Podiatry Surgery. Cleveland, Ohio 44106.

3 PGY III, Department Of Veterans Affairs. Louis Stokes Cleveland Medical Center. Podiatry Surgery . Cleveland, Ohio 44106.
The most common injury occurs during downhill skiing. If the injury is left untreated, it can lead to chronic pain or ankle pain that will require surgical correction. Pain is caused by splitting or fraying of the peroneal tendons which occur when the tendon continues to sublux over the posterior lateral edge of the fibula causing micro tears to the tendon. Chronic injuries are also associated with patients who are prone to multiple ankle sprains. These sprains can lead to lateral ankle weakness which can lead to inflammation of the peroneal tendon sheath. ${ }^{6,8,9}$ The sustained inflammation of the sheath can lead to weakening and stretching of superior peroneal retinaculum which will allow the peroneal tendons to leave the peroneal tunnel. Echard and Davis created a classification system for peroneal subluxation.

This system includes for subtypes which are as follows:

I-Periosteum is elevated form underlying malleolus.

II-Superior peroneal retinaculum is torn from the anterior insertion.

III-Superior peritoneal retinaculum is avulsed with a small piece of bone.

IV-Superior peroneal retinaculum is avulsed from posterior attachment and tendon dislocates.

(C) The Foot and Ankle Online Journal, 2009 


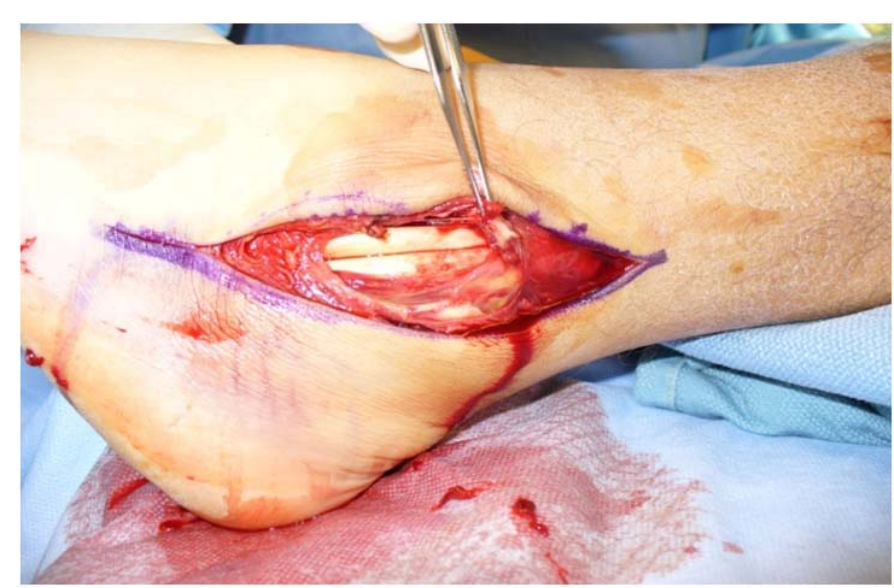

Figure 1 10-12 cm incision along the peroneal tendons.

Conservative treatment of this condition can be used however the literature shows there is a high failure rate for this course of action. ${ }^{2}$ Most conservative treatment includes casting for 4-6 weeks. Other treatment includes taping which as a lower success rate than casting. Usually primary repair is indicated for tears in the tendon involving $50 \%$ or less. ${ }^{11}$ Considering the majority of these patients are athletes, most want a speedy return to activity and expect a high success rate. ${ }^{1,8,9,10}$

\section{Case Report}

A male patient reported that he was racing his motocross bike when he landed a jump with his foot in an awkward position. He recalls extreme pain at his ankle and noted that a bone was protruding under his skin, which he states that he pushed the bone back in to place and went to the emergency room (ER).

At the ER it was noted that patient had significant swelling, pain on palpation, ecchymosis, popping sensation along with extreme instability. Patient was immobilized, obtained a magnetic resonance image (MRI) and sent to the office the next day for consultation. After educating the patient on conservative and surgical options, the patient chose the latter. MRI showed extreme poster lateral edema, and anterior talofibular ligament (ATFL) tear, avulsion fracture of fibula, with a high suspicion of SPR tear.

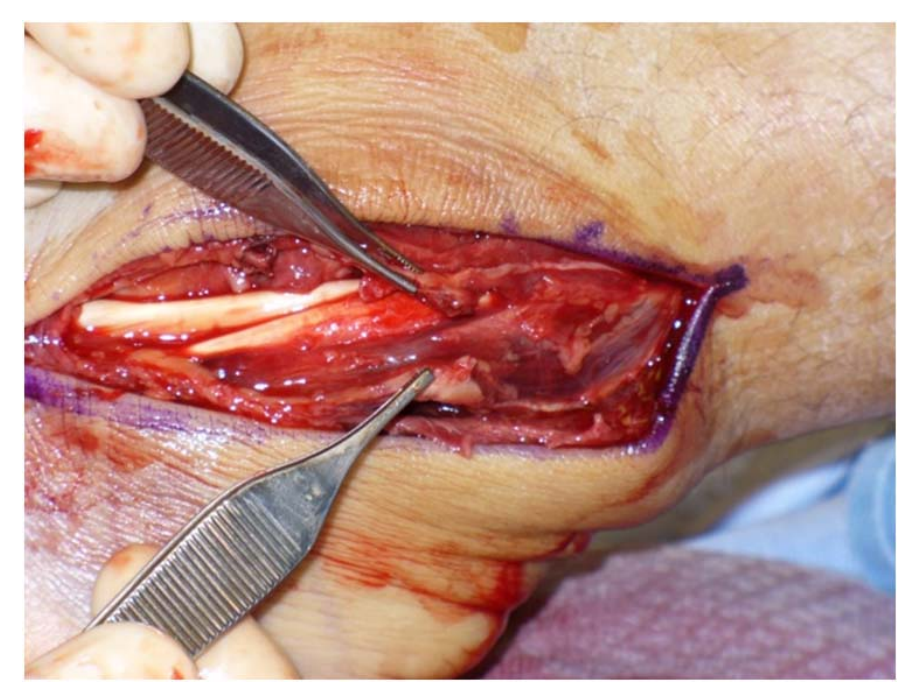

Figure 2 Resection of low lying muscle belly.

Clinical evaluation reveals a 5'11" male who is 195 lbs. The patient's neurovascular status remains intact. There is significant ecchymosis, positive Mondor sign, pain on palpation of fibula, pain with range of motion and the fibula is mobile at the lateral ankle. Stress films in the operating room while the patient is under general anesthesia reveals a positive anterior drawer and talar tilt.

\section{Surgical Technique}

An incision is made over the lateral aspect of the leg following the peroneal tendons, approximately 10 $12 \mathrm{~cm}$ in length. (Fig 1.) Significant hematoma and disruption of the tissue is encountered during blunt dissection. The peroneal tendon sheath is completely ruptured, and the peroneus brevis is lying on top of the lateral aspect of the fibula. The peroneal retinaculum is ruptured with an associated fleck of bone. On closer inspection, the peroneal groove is noted to be disrupted, rough, and shallow.

The calcaneofibular ligament is intact and stable, and the posterior capsule gapped open. The ATFL is attenuated and the origin is slightly disrupted. The peroneal tendons are intact distally. 


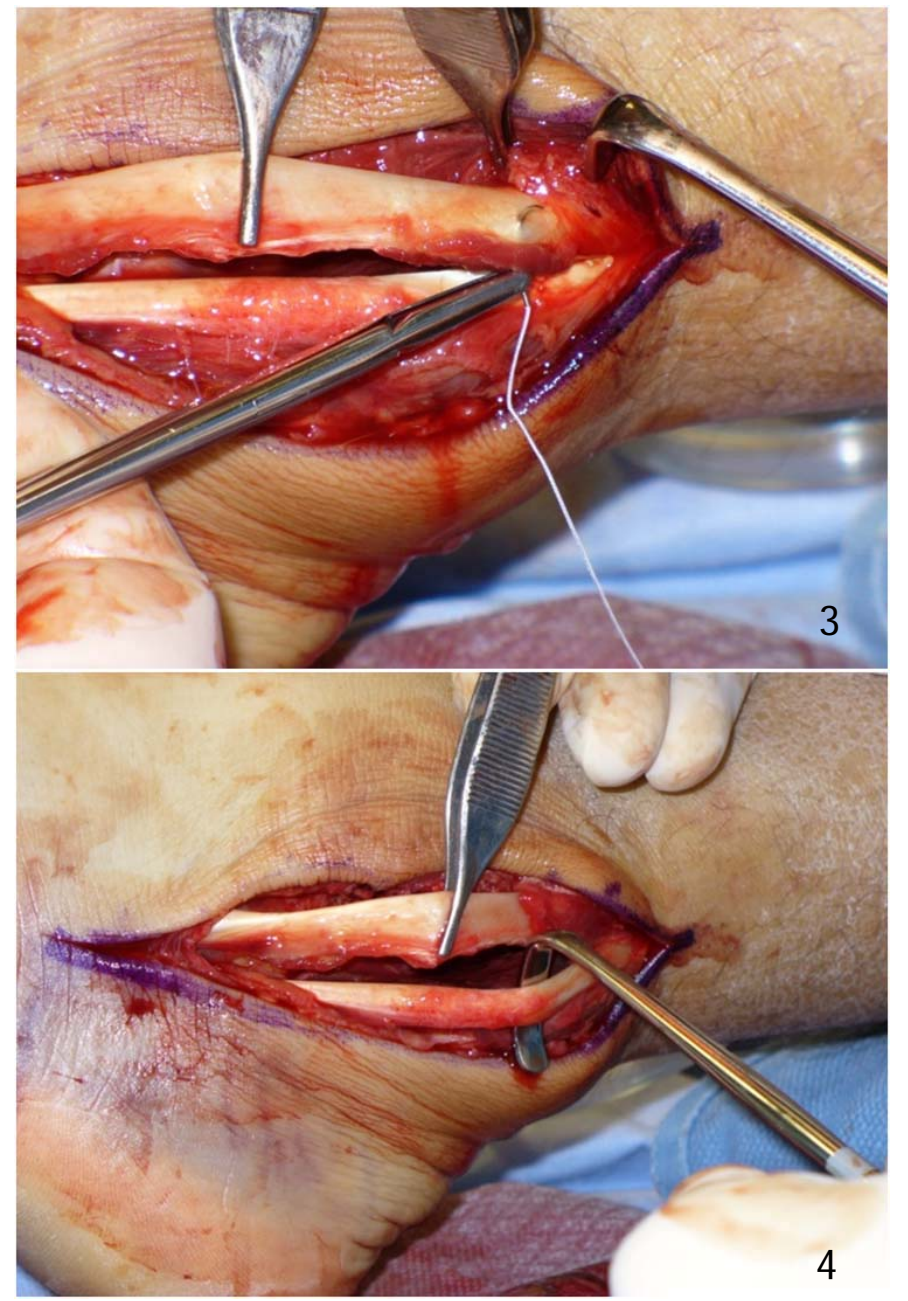

Figures 3 and 4 Repair of the peroneal tendons through tubularization.

The damaged peroneal tendon are then tubularized using \#2 fiber wire and placed back onto the fibular groove (Figs. 3,4). Subluxation and popping of the tendon is still noted. Because of this a reconstruction using the lateral $20 \%$ of the Achilles tendon is performed. A transverse incision is made into the Achilles tendon approximately $8 \mathrm{~cm}$ proximal to the insertion. The tendon is split distally and dissected through blunt means and used to protect the sural nerve and lateral structures. The low-lying muscle belly of the peroneus brevis, which is dissected away from the tendon just enough to pass the Achilles slip through its course. (Fig. 2) The cut end of the Achilles tendon is passed under the muscle belly of the peroneus brevis and over the peroneus longus and brevis tendons. (Figs. 5 and 6 )

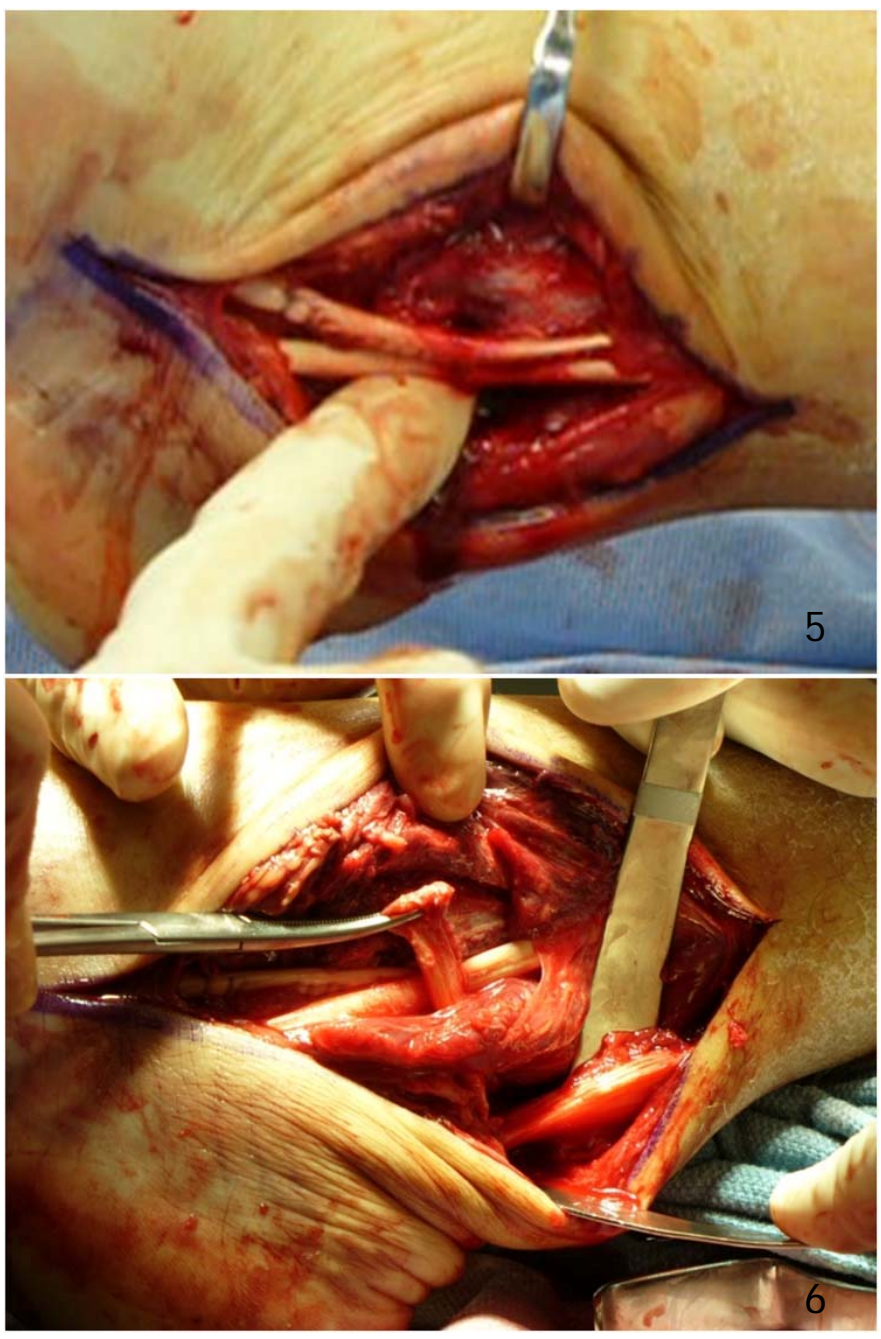

Figures 5 and $6 \mathrm{~A}$ tunnel is made through the peroneus brevis muscle belly and the slip of the Achilles tendon is then passed over the peroneal tendons.

This bridge of tendon over the peroneal tendons is then anchored to the lateral malleolus using an Arthrex ${ }^{\circledR}$ bioabsorbable anchor. (Figs. 7,8 and 9) At completion of this reconstruction, there is no sign of subluxation of the peroneal tendons.

The wound is then irrigated and a modified Brostrom technique is used to repair and tighten the ligaments in a pants-over-vest fashion. This greatly increases the tension strength of the repair. The wound is then closed in layers. 

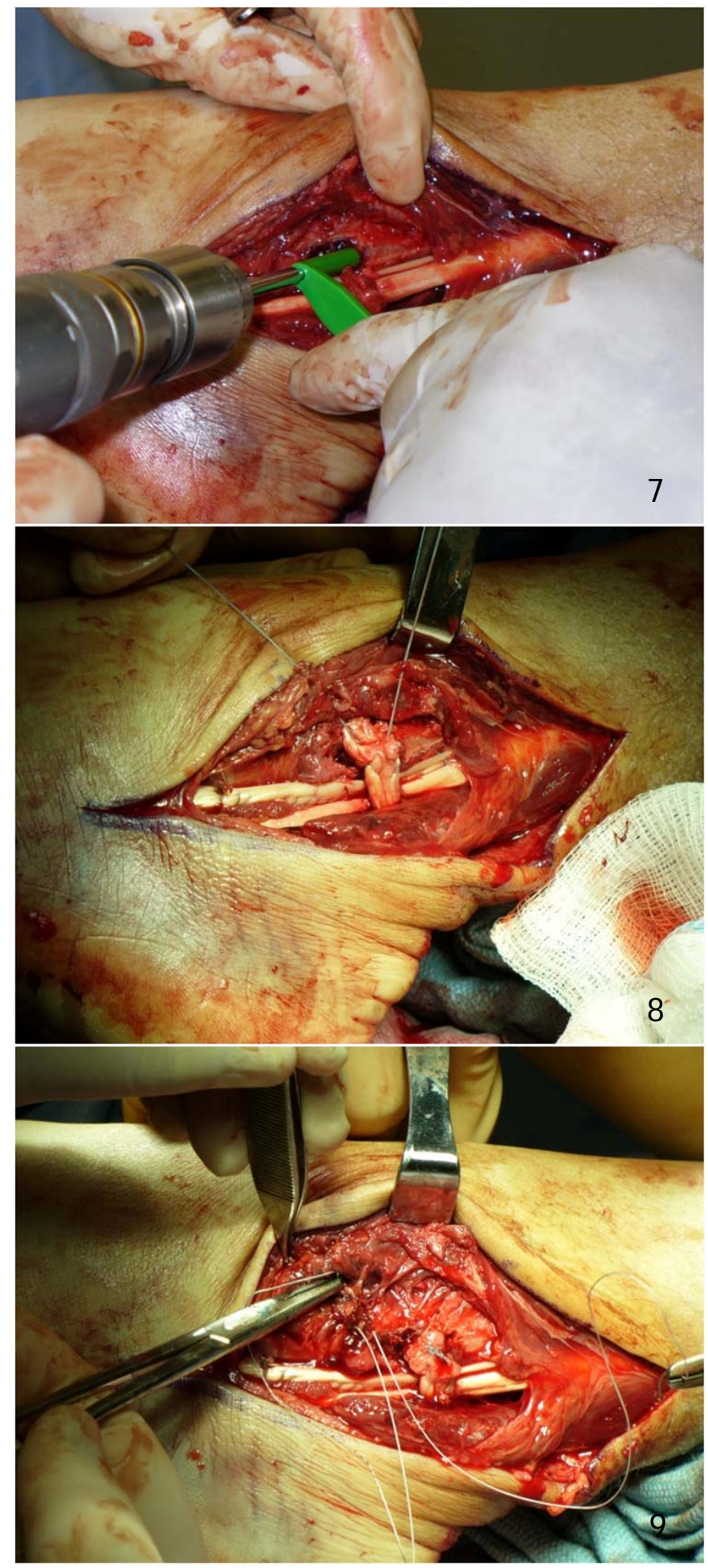

Figures 7, 8 and 9 Bone anchor is used to anchor the repair. The procedure is strengthened with a Modified Brostrom repair.

\section{Discussion}

There have been many options reported for surgical repair of peroneal subluxation or dislocation. These include direct repair of peroneal retinaculum, reconstruction of peroneal retinaculum, bone block (lateral malleolus, sliding graft), and groove deepening and rerouting procedures. ${ }^{1,2,4,6,9}$ Each of these procedures have their strengths and weaknesses. Acute repair of the superficial peroneal retinaculum is a simple repair however it may not be able to fix the underlying problem if there is a shallow grove, or the superior peroneal retinaculum itself is inherently weak due to prolonged inflammation. Reconstruction of the peroneal tendon can be accomplished using the peroneus brevis, plantaris, and/or Achilles tendons. There have been few studies reported on these techniques. A concomitant soft tissue procedure is a rerouting technique using the calcaneal fibular ligament. Bone block procedures incorporate part of an osteotomy used to deepen the fibular grove. This was first described by Kelly, and then modified by DuVries. ${ }^{1,6,9,10}$ Complications associated with these techniques include graft fracture, tendonitis, pain and re-subluxation. Groove deepening procedures are performed by removing bone from the posterior aspect of the fibula. The result of deepening this grove is a more stable tunnel for the peroneus brevis and longus tendon sheath for gliding.

Peroneal tendon subluxation and dislocation is a condition which can be easily misdiagnosed as an ankle sprain and may cause a chronic painful condition requiring surgical intervention. As foot and ankle specialists we need to have a high suspicion, particularly in the younger athletic patients prone to such injuries. The two most inherent causes of peroneal subluxation are multiple lateral ankle sprains and a shallow peroneal grove at the distal aspect of the tibia. Conservative treatment for this condition does not report a high success rate. The patient healed satisfactorily utilizing a lateral slip of the Achilles tendon in a tissue transfer technique and at the short term 6 month post op visit the patient had no complaints of pain. 


\section{References}

1. Butler BW, Lanthier J, Wertheimer SJ: Subluxing peroneals: A review of the literature and case report. J Foot Ankle Surg 32: (2):134 - 139, 1993.

2 Oliva F, Ferran N, Maffulli N: Peroneal retinaculoplasty with anchors for peroneal tendon subluxation. Bull Hosp Joint

Disease 63: $(3-4): 113-116,2006$.

3. Ferran NA, Maffulli N, Oliva F: Management of recurrent subluxation of the peroneal tendons. Foot Ankle Clinics 11: (3) $465-474,2006$.

4. Kollias SL, Ferkel RD: Fibular grooving for recurrent peroneal tendon subluxation. Am J Sports Medicine 25: (3):329 - 335, 1996.

5. Brage ME, Hansen ST Jr: Traumatic subluxation/dislocation of the peroneal tendons. Foot Ankle Online 13: (7): 423 - 431, 1992.

6. Tan V, Lin SS, Okereke E: Superior peroneal retinaculoplasty: a surgical technique for peroneal subluxation. Clinical Ortho Rel Res [serial online] 410: 320 - 325, 2003.

7. Krause JO, Brodsky JW: peroneus brevis tendon tears:

Pathophysiology, surgical reconstruction, and clinical results.

Foot Ankle Int 19: (5): 271 - 279, 1998.

8. Ferran NA, Maffulli N, Oliva F: Management of recurrent subluxation of the peroneal tendons. Foot Ankle Clinics [serial online]11: (3):465 - 474, 2006.

9. Niemi WJ, Savidakis J Jr, DeJesus JM: Peroneal subluxation: a comprehensive review of the literature with case presentations. J Foot Ankle Surg 36: (2): 141 - 145, 1997.

10. Porter D, McCarroll J, Knapp E, Torma J: Peroneal tendon subluxation in athletes: fibular groove deepening and retinacular reconstruction. Foot Ankle Int 26: (6): 436 - 441, 2005.

11. Heckman DS, Reddy S, Pedowitz D, Wapner KL, Parekh SG: Operative treatment for peroneal tendon disorders. J Bone Joint Surg 90A: (2): 404 - 418, 2008.

12. Mendicino RW, Orsini RC, Whitman SE, Catanzariti AR:

Fibular groove deepening for recurrent peroneal subluxation. J

Foot Ankle Surg 40: (4):252 - 263, 2001. 